\title{
Association between body mass index and mortality among institutionalized elderly adults in Japan
}

\author{
Akemi Nakazawa $\cdot$ Kazutoshi Nakamura \\ Kaori Kitamura $\cdot$ Yoshiaki Yoshizawa
}

Received: 12 March 2013/ Accepted: 5 July 2013/Published online: 27 July 2013

(c) The Japanese Society for Hygiene 2013

\begin{abstract}
Background The purpose of this study is to assess the association between body mass index (BMI) and mortality among nursing home residents in Japan.

Methods A one-year prospective cohort study was conducted with 8,510 elderly individuals across 140 nursing homes. Baseline measurements included age, sex, height, weight, BMI, activities of daily living (ADL) (Barthel Index), and degree of dementia. Information regarding dates of discharge and mortality were also obtained to calculate person-years. Cox's proportional hazards model was used to estimate hazard ratios.

Results Mean age and BMI were 84.3 [standard deviation (SD) 8.1] years and $20.6(\mathrm{SD} 3.8) \mathrm{kg} / \mathrm{m}^{2}$, respectively. Hazard ratios of mortality adjusted for sex, age, ADL, degree of dementia, and type of home were 2.4 [95\% confidence interval (CI): 1.9-3.1] for the 1st quintile of BMI $\left(<17.3 \mathrm{~kg} / \mathrm{m}^{2}\right), 1.7$ (95\% CI: $\left.1.3-2.3\right)$ for the $2 \mathrm{nd}$ quintile $\left(17.3-19.2 \mathrm{~kg} / \mathrm{m}^{2}\right), 1.5$ (95\% CI: $\left.1.2-2.0\right)$ for the 3rd quintile $\left(19.3-21.1 \mathrm{~kg} / \mathrm{m}^{2}\right)$, and 1.2 (95\% CI: 0.9-1.6) for the 4th quintile $\left(21.2-23.5 \mathrm{~kg} / \mathrm{m}^{2}\right)(P$ for trend $<0.001)$, compared with the reference 5 th quintile $\left(23.6 \leq \mathrm{kg} / \mathrm{m}^{2}\right)$.
\end{abstract}

\footnotetext{
A. Nakazawa

Department of Nursing, Faculty of Health Sciences, Ryotokuji

University, 5-8-1 Akemi, Urayasu 279-8567, Japan

K. Nakamura $(\bowtie) \cdot$ K. Kitamura

Division of Preventive Medicine, Niigata University Graduate

School of Medical and Dental Sciences, 1-757 Asahimachi-dori,

Chuo-ku, Niigata 951-8510, Japan

e-mail: kazun@med.niigata-u.ac.jp

Y. Yoshizawa

Niigata Council of Institutions for the Elderly,

2-2-2 Kamitokoro, Chuo-ku, Niigata 950-0994, Japan
}

Conclusions There was a clear inverse dose-dependent relationship between BMI and mortality. Future studies should be conducted to determine the effects of nutritional intervention on mortality in institutionalized elderly adults.

Keywords BMI · Cohort studies · Frail elderly · Nursing homes $\cdot$ Mortality

\section{Introduction}

The rapidly growing elderly population in Japan has been accompanied by an increase in the proportion of frail elderly people. In fact, the number of special nursing homes in 2010 was reported to be 5,978 , with more than 410,000 residents [1]. In this context, identifying predictors of mortality among institutionalized elderly people is meaningful not only for their health, but also for caregivers to provide appropriate care.

Body mass index (BMI) is an important parameter for characterizing the health status of frail elderly individuals. Several studies have indicated that low BMI is associated with increased mortality risk in nursing home residents [25]. However, its impact on mortality risk is not uniform in these studies, and may reflect different sample sizes across studies (range of $n=82-519$ ) [2-5]. Ethnic differences may also account for this variability.

We previously conducted a nursing-home-based, largescale cohort study and found an association between levels of activities of daily living (ADL) and one-year mortality [6]. In the present cohort study, we further analyzed the impact of BMI on mortality. Accordingly, the aim of this study is to determine whether BMI is associated with mortality in nursing home residents in Japan. 


\section{Methods}

Nursing home residents living in all 201 nursing homes registered with the Niigata Council of Institutions for the Elderly in Niigata Prefecture, Japan, were targeted in this study. Of the 201 nursing homes, 140 (8,905 elderly individuals) participated. The final participant population consisted of 8,510 elderly individuals, after excluding 395 for whom BMI could not be evaluated (due mainly to their bedridden status). The study protocol was approved by the independent Ethics Committee of Niigata University School of Medicine. Details of the study protocol have been published previously [6].

The present study was conducted from April 1, 2007 to March 31, 2008. Age, sex, height, and weight of participants were obtained from medical records. BMI was calculated as weight $(\mathrm{kg})$ divided by height squared $\left(\mathrm{m}^{2}\right)$. ADL levels were determined using the Barthel Index [7], which consists of 10 items: feeding, transfers, grooming, toilet use, bathing, mobility, stair use, dressing, and bowel and bladder control. The level of assistance (ranging from complete assistance to independence) required for each item was scored on a 2- to 4-point scale on which a maximal level of assistance (totally dependent) was scored as 0 points and a minimal level as 100 points. Degree of dementia was assessed using a scale provided by the Ministry of Health, Labor, and Welfare of Japan [8], which includes 5 categories: no dementia (normal), some dementia but almost independent in daily living (I, slight), dementia with some difficulty communicating but independent in daily living with minimal observation (II, light), dementia with some difficulty communicating and requiring partial care (III, moderate), and severe dementia with difficulty communicating and requiring complete care (IV, severe). During the one-year follow-up period, each nursing home reported information on dates of discharge and mortality, which was used to calculate person-years on a daily basis.
Mortality rate was calculated as the number of mortalities divided by person-years. Cox's proportional hazards model was used to estimate unadjusted and adjusted hazard ratios (HRs). Statistical Analysis Software (SAS; release 9.13, SAS Institute Inc., Cary, NC, USA) was used for data analysis. $P<0.05$ was considered statistically significant.

\section{Results}

Mean age and BMI were 84.3 (SD 8.1) years and 20.6 (SD 3.8) $\mathrm{kg} / \mathrm{m}^{2}$, respectively. Baseline participant characteristics by quintiles of BMI are presented in Table 1. All variables, with the exception of sex, were associated with BMI. Of the 8,510 participants, 1,079 died during the oneyear follow-up period.

Adjusted HRs of mortality according to BMI quintiles are presented in Table 2. BMI was inversely associated with mortality, regardless of adjustment. HRs decreased with an increasing number of adjusted covariates. After adjusting for all covariates, HRs significantly increased with decreases of BMI $<21.2 \mathrm{~kg} / \mathrm{m}^{2}$. HRs for Q1-Q3 (BMI $<21.2 \mathrm{~kg} / \mathrm{m}^{2}$ ) were significantly higher than that of the reference group (Q5).

Given that very low levels of ADL and dementia are considered strong predictors of mortality [6], HRs of mortality according to BMI quintiles were recalculated by excluding totally dependent participants (total Barthel Index $=0$ ) and participants with severe (level IV) dementia (Table 3). Similar to the results in Table 2, adjusted HRs significantly increased with decreases of BMI. These HRs were stratified by Barthel Index levels (above or below the median value of 60), and are also presented in Table 3 . The lowest mortality was observed in the fourth quartile (BMI 23.1-25.2 $\mathrm{kg} / \mathrm{m}^{2}$ ) in the subgroup of Barthel Index $\geq 60$, and thus this quartile was used as a reference in this subgroup. In both Barthel Index

Table 1 Baseline subject characteristics (mean with SD or proportion) by quintiles of body mass index (BMI)

\begin{tabular}{|c|c|c|c|c|c|c|}
\hline & \multicolumn{5}{|c|}{ Quintiles of BMI $\left(\mathrm{kg} / \mathrm{m}^{2}\right)$} & \multirow[t]{2}{*}{$P$ for trend } \\
\hline & Q1 $(<17.3)$ & Q2 (17.3-19.2) & Q3 (19.3-21.1) & Q4 (21.2-23.5) & Q5 $(23.6 \leq)$ & \\
\hline Women $(\%)$ & 77.7 & 77.3 & 75.6 & 75.6 & 78.0 & 0.7259 \\
\hline Age (years) & $84.8(\mathrm{SD} 8.2)$ & $85.2(\mathrm{SD} 7.9)$ & $84.8(\mathrm{SD} 8.1)$ & $83.8(\mathrm{SD} 8.0)$ & $82.7(\mathrm{SD} 8.0)$ & $<0.0001$ \\
\hline Height (cm) & $148.1(\mathrm{SD} 9.0)$ & $146.6(\mathrm{SD} 9.2)$ & $145.7(\mathrm{SD} 9.5)$ & $145.0(\mathrm{SD} 9.3)$ & 143.7 (SD 9.7) & $<0.0001$ \\
\hline Weight $(\mathrm{kg})$ & $34.4(\mathrm{SD} 4.9)$ & 39.8 (SD 5.2) & $43.2(\mathrm{SD} 5.7)$ & $47.1(\mathrm{SD} 6.2)$ & $54.1(\mathrm{SD} 8.3)$ & $<0.0001$ \\
\hline BMI $\left(\mathrm{kg} / \mathrm{m}^{2}\right)$ & $15.7(\mathrm{SD} 1.3)$ & $18.4(\mathrm{SD} 0.6)$ & $20.3(\mathrm{SD} 0.5)$ & $22.3(\mathrm{SD} 0.7)$ & $26.1(\mathrm{SD} 2.3)$ & $<0.0001$ \\
\hline Total Barthel Index & $18.4(\mathrm{SD} 29.6)$ & $28.1(\mathrm{SD} 34.3)$ & $37.7(\mathrm{SD} 36.8)$ & $47.3(\mathrm{SD} 38.3)$ & $60.4(\mathrm{SD} 35.3)$ & $<0.0001$ \\
\hline No or slight dementia $(\%)$ & 11.8 & 15.4 & 21.8 & 30.8 & 43.4 & $<0.0001$ \\
\hline
\end{tabular}


Table 2 Hazard ratios (HRs) of mortality at one-year follow-up according to quintiles of body mass index (BMI)

\begin{tabular}{|c|c|c|c|c|c|c|}
\hline & \multicolumn{5}{|c|}{ Quintiles of BMI $\left(\mathrm{kg} / \mathrm{m}^{2}\right)$} & \multirow[t]{2}{*}{$P$ for trend } \\
\hline & Q1 $(<17.3)$ & Q2 (17.3-19.2) & Q3 (19.3-21.1) & Q4 (21.2-23.5) & Q5 $(23.6 \leq)$ & \\
\hline Number of deaths & 405 & 256 & 197 & 136 & 85 & \\
\hline Person-years & 1,453 & 1,552 & 1,577 & 1,604 & 1,640 & \\
\hline Mortality rate (/1000 person-years) & 278.7 & 164.9 & 124.9 & 84.8 & 51.8 & \\
\hline $\begin{array}{l}\text { Unadjusted HR } \\
(95 \% \mathrm{CI})\end{array}$ & $\begin{array}{l}5.4 \\
(4.3-6.8)\end{array}$ & $\begin{array}{l}3.2 \\
(2.5-4.1)\end{array}$ & $\begin{array}{l}2.4 \\
(1.9-3.1)\end{array}$ & $\begin{array}{l}1.6 \\
(1.3-2.2)\end{array}$ & 1 (Ref.) & $<0.0001$ \\
\hline $\begin{array}{l}\text { Adjusted } \mathrm{HR}^{\mathrm{a}} \\
(95 \% \mathrm{CI})\end{array}$ & $\begin{array}{l}4.9 \\
(3.9-6.2)\end{array}$ & $\begin{array}{l}2.9 \\
(2.2-3.7)\end{array}$ & $\begin{array}{l}2.1 \\
(1.6-2.7)\end{array}$ & $\begin{array}{l}1.5 \\
(1.1-2.0)\end{array}$ & 1 (Ref.) & $<0.0001$ \\
\hline $\begin{array}{l}\text { Adjusted } \mathrm{HR}^{\mathrm{b}} \\
(95 \% \mathrm{CI})\end{array}$ & $\begin{array}{l}2.4 \\
(1.9-3.1)\end{array}$ & $\begin{array}{l}1.8 \\
(1.3-2.3)\end{array}$ & $\begin{array}{l}1.5 \\
(1.1-1.9)\end{array}$ & $\begin{array}{l}1.2 \\
(0.9-1.6)\end{array}$ & 1 (Ref.) & $<0.0001$ \\
\hline $\begin{array}{l}\text { Adjusted } \mathrm{HR}^{\mathrm{c}} \\
(95 \% \mathrm{CI})\end{array}$ & $\begin{array}{l}2.4 \\
(1.9-3.1)\end{array}$ & $\begin{array}{l}1.7 \\
(1.3-2.3)\end{array}$ & $\begin{array}{l}1.5 \\
(1.2-2.0)\end{array}$ & $\begin{array}{l}1.2 \\
(0.9-1.6)\end{array}$ & 1 (Ref.) & $<0.0001$ \\
\hline
\end{tabular}

a Adjusted for sex and age

b Adjusted for sex, age, and total Barthel Index

c Adjusted for sex, age, total Barthel Index, degree of dementia, and type of home

subgroups, adjusted HRs significantly increased with decreases of BMI, and the first quartile had the highest mortality.

\section{Discussion}

A clear inverse dose-dependent relationship was identified between BMI and mortality in a population of institutionalized elderly adults. Some cohort studies have reported increased relative risks of mortality with low BMI; For instance, Grabowski et al. [9] showed that noninstitutionalized Americans aged $>70$ years with BMI $<19.4 \mathrm{~kg} / \mathrm{m}^{2}$ ( $n=7,527$ ) had a 1.5 -fold higher risk of mortality compared with those with normal BMI. Al Snih et al. [10] also showed that community-dwelling Americans aged $>65$ years with $\mathrm{BMI}<18.5 \mathrm{~kg} / \mathrm{m}^{2}(n=12,725)$ had a 1.5 fold higher risk of mortality compared with those with normal BMI. Other studies have targeted institutionalized residents. Flacker and Kiely [11] showed that nursing home residents in the USA with BMI $<23 \mathrm{~kg} / \mathrm{m}^{2}(n=60,341)$ had a 1.3-1.5-fold higher risk of mortality, and Cereda et al. [2] showed that institutionalized Italians aged $>65$ years with BMI $<21 \mathrm{~kg} / \mathrm{m}^{2}(n=519)$ had a 1.5 -fold higher risk of mortality. These relative risks are similar to our adjusted HRs of 1.7 (2nd quintile; BMI range, $17.3-19.2 \mathrm{~kg} / \mathrm{m}^{2}$ ) and 1.5 (3rd quintile; BMI range, $19.3-21.1 \mathrm{~kg} / \mathrm{m}^{2}$ ).

Previous cohort studies targeting Asians are more relevant, in terms of environmental and genetic aspects, to our results for comparative purposes. Chan et al. [4], studying 154 elderly Singaporeans, showed that BMI $<18.5 \mathrm{~kg} / \mathrm{m}^{2}$ is associated with a 2.7-fold higher risk of mortality, which is comparable to our adjusted HR of 2.4 (1st quintile; BMI $<17.3 \mathrm{~kg} / \mathrm{m}^{2}$ ). Low BMI, such as $<17.3 \mathrm{~kg} / \mathrm{m}^{2}$ in the present population, is considered a critical risk factor of mortality in institutionalized elderly Japanese individuals.

In contrast to our results, Al Snih et al. [10] showed a U-shaped association between BMI and mortality in a US elderly population and suggested that BMI within the range $25-30 \mathrm{~kg} / \mathrm{m}^{2}$ was associated with the lowest mortality. Almost all (98.7\%) subjects in the present study had BMI $<30 \mathrm{~kg} / \mathrm{m}^{2}$, thus the results are more suggestive of a dosedependent association, rather than a U-shaped one. It should be noted, however, that our subgroup analysis (Table 3) indicated that the BMI $23.1-25.2 \mathrm{~kg} / \mathrm{m}^{2}$ group had the lowest mortality. Although obesity does not seem to be a critical health problem in institutionalized elderly Japanese people, BMI between 23 and $25 \mathrm{~kg} / \mathrm{m}^{2}$ may be ideal in such populations.

Smoking may be associated with both mortality and BMI [12], and thus is a potential confounder in this study. We did not, however, assess smoking status. Nonetheless, the effects of smoking on mortality are likely small, given the low smoking rate among Japanese elderly (as low as $19 \%$ in men and $3 \%$ in women aged $\geq 70$ years) [13]. Other unknown cofounders may also exist, including comorbid diseases such as cerebrovascular disease, heart disease, and diabetes [14, 15]. Future studies should take these potential cofounders into account.

The link between low BMI and increased mortality risk is likely established through multiple pathways; For example, low BMI is associated with malnourishment, which in turn may reduce immunological function and cause related diseases. In addition, BMI-related conditions, such as comorbidities and smoking status which were not 
Table 3 Hazard ratios (HRs) of mortality at one-year follow-up by quintiles of body mass index (BMI) excluding subjects who are totally dependent (total Barthel Index $=0$ ) or have severe dementia (level IV), and those HRs stratified by Barthel index levels (above or below median)

\begin{tabular}{|c|c|c|c|c|c|c|}
\hline & \multicolumn{5}{|c|}{ Quintiles of BMI $\left(\mathrm{kg} / \mathrm{m}^{2}\right)$} & \multirow[t]{2}{*}{$P$ for trend ${ }^{\mathrm{a}}$} \\
\hline & Q1 $(<18.3)$ & Q2 (18.3-20.2) & Q3 (20.3-22.0) & Q4 (22.1-24.4) & Q5 $(24.5 \leq)$ & \\
\hline \multicolumn{7}{|l|}{ All data } \\
\hline Number of deaths & 147 & 107 & 79 & 54 & 36 & \\
\hline Person-years & 986 & 1,005 & 1,016 & 1,039 & 1,046 & \\
\hline Mortality rate (/1000 person-years) & 149.2 & 106.5 & 77.8 & 52.0 & 34.4 & \\
\hline Unadjusted HR (95 \% CI) & $4.4(3.0-6.3)$ & $3.1(2.1-4.5)$ & $2.3(1.5-3.4)$ & $1.5(1.0-2.3)$ & 1 (Ref.) & $<0.0001$ \\
\hline \multirow[t]{2}{*}{ Adjusted $\mathrm{HR}^{\mathrm{a}}(95 \% \mathrm{CI})$} & $2.7(1.9-4.0)$ & $2.0(1.4-2.9)$ & $1.7(1.1-2.5)$ & $1.3(0.9-2.1)$ & 1 (Ref.) & $<0.0001$ \\
\hline & Q1 $(<17.5)$ & Q2 (17.5-19.3) & Q3 (19.4-21.1) & Q4 (21.2-23.3) & \multicolumn{2}{|l|}{ Q5 $(23.4 \leq)$} \\
\hline \multicolumn{7}{|l|}{ Barthel index $>0,<60$ (median) } \\
\hline Number of deaths & 106 & 60 & 71 & 49 & 33 & \\
\hline Person-years & 462 & 483 & 485 & 491 & 503 & \\
\hline Mortality rate (/1000 person-years) & 229.6 & 124.2 & 146.3 & 99.8 & 65.6 & \\
\hline Unadjusted HR (95 \% CI) & $3.5(2.4-5.2)$ & $1.9(1.2-2.9)$ & $2.2(1.5-3.4)$ & $1.5(1.0-2.4)$ & 1 (Ref.) & $<0.0001$ \\
\hline \multirow[t]{2}{*}{ Adjusted $\mathrm{HR}^{\mathrm{a}}(95 \% \mathrm{CI})$} & $3.3(2.2-4.9)$ & $1.5(1.0-2.3)$ & $2.1(1.4-3.2)$ & $1.5(0.9-2.3)$ & 1 (Ref.) & $<0.0001$ \\
\hline & Q1 (<19.3) & Q2 (19.3-21.1) & Q3 (21.2-23.0) & Q4 (23.1-25.2) & \multicolumn{2}{|l|}{ Q5 $(25.3 \leq)$} \\
\hline \multicolumn{7}{|l|}{ Barthel index $\geq 60$ (median) } \\
\hline Number of deaths & 35 & 22 & 22 & 9 & 16 & \\
\hline Person-years & 526 & 529 & 532 & 542 & 538 & \\
\hline Mortality rate (/1000 person-years) & 66.6 & 41.6 & 41.4 & 16.6 & 29.7 & \\
\hline Unadjusted HR (95 \% CI) & $4.0(1.9-8.4)$ & $2.5(1.2-5.5)$ & $2.5(1.2-5.4)$ & 1 (Ref.) & $1.8(0.8-4.1)$ & 0.0003 \\
\hline Adjusted $\mathrm{HR}^{\mathrm{a}}(95 \% \mathrm{CI})$ & $3.5(1.7-7.4)$ & $2.4(1.1-5.1)$ & $2.4(1.1-5.2)$ & 1 (Ref.) & $2.0(0.9-4.6)$ & 0.0037 \\
\hline
\end{tabular}

${ }^{a}$ Adjusted for sex, age, total Barthel Index, degree of dementia, and type of home

controlled for in this study, may also contribute to increased mortality risk.

The strength of this study is that it is the first cohort study in Japan and the first large-scale cohort study in Asia to determine the impact and mode of association between BMI and mortality among institutionalized elderly people. Limitations of this study include the use of short-term mortality as an endpoint and the lack of disease information. Such information, if available, may have allowed for a more sensitive prediction of mortality, particularly because wasting diseases are known to decrease BMI. We attempted to address this by assessing the association within participants who have better ADL levels (Table 3) and thus are less likely to have wasting diseases, and confirmed a strong association between low BMI and increased mortality. Moreover, given that, as discussed above, low BMI may have resulted from diseases, the diseases themselves may be more important predictors of mortality. Despite these limitations, we believe that our results will aid nursing home staff and physicians in developing care plans and addressing future healthcare needs.
We found a clear inverse dose-dependent relationship between BMI and mortality in nursing home residents. Although we did not determine a cutoff point for increased mortality risk, BMI $<17.3 \mathrm{~kg} / \mathrm{m}^{2}$ may represent an apparent high risk $(\mathrm{HR}=2.4)$. Future research should determine the effects of nutritional intervention on mortality in institutionalized elderly adults.

Acknowledgments We thank the Niigata Council of Institutions for the Elderly for their assistance in data collection. This study was supported in part by a grant from the Chiyoda Mutual Life Foundation, 2006.

Conflict of Interest The authors declare that they have no conflict of interest.

\section{References}

1. Health and Welfare Statistics Association 2012/2013. Kokuminno-Fukushi-to-Kaigo-no-Doko. Tokyo: Health and Welfare Statistics Association; 2012 (in Japanese). 
2. Cereda E, Pedrolli C, Zagami A, Vanotti A, Piffer S, Opizzi A, Rondanelli M, Caccialanza R. Body mass index and mortality in institutionalized elderly. J Am Med Dir Assoc. 2011;12:174-8.

3. Kaiser R, Winning K, Uter W, Volkert D, Lesser S, Stehle P, Kaiser MJ, Sieber CC, Bauer JM. Functionality and mortality in obese nursing home residents: an example of 'risk factor paradox'? J Am Med Dir Assoc. 2010;11:428-35.

4. Chan M, Lim YP, Ernest A, Tan TL. Nutritional assessment in an Asian nursing home and its association with mortality. J Nutr Health Aging. 2010;14:23-8.

5. Kimyagarov S, Klid R, Levenkrohn S, Fleissig Y, Kopel B, Arad M, Adunsky A. Body mass index (BMI), body composition and mortality of nursing home elderly residents. Arch Gerontol Geriatr. 2010;51:227-30.

6. Nakazawa A, Nakamura K, Kitamura K, Yoshizawa Y. Association between activities of daily living and mortality among institutionalized elderly adults in Japan. J Epidemiol. 2012;22:501-7.

7. Mahoney FI, Barthel DW. Functional evaluation: the Barthel index. Md State Med J. 1965;14:61-5.

8. Takigawa Y. Criteria for independence of demented elderly people (authors' translation). Koshu-Eisei (J Public Health Pract). 1994;58:73-5 (in Japanese).
9. Grabowski DC, Ellis JE. High body mass index does not predict mortality in older people: analysis of the Longitudinal Study of Aging. J Am Geriatr Soc. 2001;49:968-79.

10. AlSnih S, Ottenbacher KJ, Markides KS, Kuo YF, Eschbach K, Goodwin JS. The effect of obesity on disability vs mortality in older Americans. Arch Intern Med. 2007;167:774-80.

11. Flacker JM, Kiely DK. Mortality-related factors and 1-year survival in nursing home residents. J Am Geriatr Soc. 2003;51:213-21.

12. $\mathrm{Xu} \mathrm{F}$, Yin $\mathrm{XM}$, Wang $\mathrm{Y}$. The association between amount of cigarettes smoked and overweight, central obesity among Chinese adults in Nanjing, China. Asia Pac J Clin Nutr. 2007;16:240-7.

13. Society for Information on Health and Nutrition. The National Health and Nutrition Survey in Japan, 2008. Tokyo: Daiichi Shuppan; 2011 (in Japanese).

14. Stineman MG, Xie D, Pan Q, Kurichi JE, Zhang Z, Saliba D, Henry-Sánchez JT, Streim J. All-cause 1-, 5-, and 10-year mortality in elderly people according to activities of daily living stage. J Am Geriatr Soc. 2012;60:485-92.

15. Kitamura K, Nakamura K, Nishiwaki T, Ueno K, Hasegawa M. Low body mass index and low serum albumin are predictive factors for short-term mortality in elderly Japanese requiring home care. Tohoku J Exp Med. 2010;221:29-34. 